\title{
Núcleo central e periferia das representações sociais de ciclos de aprendizagem entre professores
}

- Laêda Bezerra Machado*

口 Rosimere de Almeida Aniceto**

\section{Resumo}

Este artigo identifica as representações sociais de ciclos de aprendizagem entre professores de Recife e suas implicações práticas, demarcando a saliência e estrutura dessas representações. Participaram do estudo 103 professores. 0 procedimento de coleta utilizado foi a associação livre de palavras. Os dados foram processados pelo software EVOC, que oferece um gráfico com quatro quadrantes onde localizamos o provável núcleo central e sistema periférico da representação social. Os resultados apontam um discurso racionalizado, ou seja, a saliência dessa representação permite afirmar que os docentes, embora na prática critiquem e rechacem os ciclos de aprendizagem, nas suas representações revelam sintonia com a proposta da rede municipal. Sugerimos, portanto, estudos mais densos das práticas cotidianas desses docentes, para depreender aspectos das representações sociais que nos pareceram pouco revelados.

Palavras-chave: Ciclos de aprendizagem. Representações sociais. Professores.

\section{Core and periphery of social representation cycles between learning teachers Abstract}

This article identifies the social representations of cycles of learning among teachers of Recife and its practical implications, pointing out the boss and structure of these representations. Participants were 103 teachers. The collection procedure used was the free association of words. The data were processed by EVOC, which provides a chart with four quadrants where we place

\footnotetext{
* Professora Adjunta do Departamento de Administração Escolar e Planejamento Educacional, Programa de Pós-Graduação em Educação, Núcleo de Formação de Professores e Prática Pedagógica Centro de Educação, Universidade Federal de Pernambuco (UFPE). E-mail: laeda@oi.com.br

** Aluna do Curso de Pedagogia Centro de Educação, UFPE. Bolsista, Programa Institucional de Bolsas de Iniciação Científica (PIBIC/CNPq). E-mail: meyre_kate@hotmail.com
} 
the likely core and peripheral system of social representation. The results show a streamlined speech, i.e., the boss of this representation to suggest that teachers, although in practice criticize and deny the cycles of learning in their representations reveal line with the proposal of the municipal network. Therefore, we suggest denser studies of everyday practices of teachers, to infer aspects of social representations that seemed little revealed Keywords: Cycles of learning. Social Representations. Teachers.

\section{Centro y periferia de las representaciones sociales de ciclos de aprendizaje entre maestros Resumen}

El artículo identifica las representaciones sociales de los ciclos de aprendizaje entre los profesores de Recife y sus implicaciones prácticas, señalando la importancia y la estructura de estas representaciones. Los participantes fueron 103 docentes. El procedimiento de recolección utilizado fue la asociación libre de palabras. Los datos fueron procesados por software EVOC, que ofrece un gráfico con cuatro cuadrantes donde localizamos el probable núcleo central y sistema periférico de la representación social. Los resultados muestran un discurso racional, es decir, la importancia de esta representación permite afirmar que los profesores, aunque en la práctica critican y niegan los ciclos de aprendizaje, en sus representaciones muestran de acuerdo con la propuesta de la red municipal. Sugerimos, por lo tanto, los estudios más densos de las prácticas cotidianas de los profesores, para inferir aspectos de las representaciones sociales que nos parezcan poco revelados.

Palabras clave: Los ciclos de aprendizaje. Representaciones sociales. Profesores.

\section{Introdução}

A escola brasileira foi tradicionalmente organizada em series, no entanto, nos últimos anos, vem sendo introduzida uma mudança radical - o regime de ciclos de ciclos de aprendizagem. Os ciclos de aprendizagem se caracterizam como possibilidade de reorganização do tempo e espaço escolares, respeito aos processos de aprendizagem dos alunos e eliminação da repetência. A rede municipal do Recife adotou a proposta de ciclos de aprendizagem desde 2001. Este artigo tem como objetivo identificar a estrutura das representações sociais de ciclos de aprendizagem entre professores, bem como suas implicações para a prática dos docentes.

No Brasil diversas pesquisas revelam que a reprovação e evasão escolar são alarmantes para o século XXI. Estudo do Instituto Nacional de Estudos e Pesquisas Educacionais Anísio Teixeira (INEP), do Ministério da Educação (MEC) (INEP, 2003), 
revelou que 35,7 milhões de alunos estavam matriculados no Ensino Fundamental, 8,46 milhões estavam em defasagem idade/série. Os programas de correção de fluxos escolares, entre eles os ciclos de aprendizagem, destinam-se a enfrentar a distorção idade/série e o fracasso escolar tão reincidente nas populações de baixa renda no pais. Para Setúbal (2000) eles se constituem como fatores decisivos para uma efetiva educação pública inclusiva.

Barretto e Mitrulis (1999) afirmam que os ciclos surgem como forma de regularizar o fluxo escolar, buscando eliminar, ou limitar a repetência. Segundo as autoras, o objetivo é oferecer melhores condições de ensino e êxito escolar dos alunos favorecendo assim o exercício da plena cidadania.

Em que pesem as experiências pontuais de implantação de ciclos nos anos 1980 e início dos anos 1990, é somente nos últimos dez anos que essa possibilidade de organização escolar se intensificou. Isso ocorreu porque a legislação incorporou o que já se manifestava em diversos sistemas de ensino no Brasil. A atual Lei de Diretrizes e Bases (LDB) (BRASIL, 1996), sugere diferentes formas de se organizar as turmas na escola. É o que prevê, por exemplo, o seu artigo 23 quando afirma: "a educação básica poderá organizar-se em ciclos, alternância regular de períodos de estudo, grupos não seriados, com base na idade, na competência e em outros critérios ou por forma diversa de organização, sempre que o interesse do ensino aprendizagem assim o recomendar".

Arroyo (1999) afirma que os ciclos ultrapassam a lógica do sistema seriado rompendo com a fragmentação do currículo escolar, que não respeita os tempos e os espaços necessários à aprendizagem do alunado. Salienta que não é possivel interpretar 0 art. 23 da LDB sem articulá-lo aos seus artigos $1^{\circ}, 2^{\circ}$ e 22 . Segundo 0 autor, esses artigos se referem à educação básica enquanto elemento primordial ao desenvolvimento e formação humana de todos os cidadãos.

A implantação dos ciclos no Ensino Fundamental público no país tem sido frequente e aponta a pertinência de se debater seus sentidos e significados entre os atores educacionais. Conforme Mainardes (2007) o termo "ciclos" com o significado de não retenção veio a ser utilizado de modo mais recorrente na década de 1980, adquirindo posteriormente outras designações, tais como: promoção automática, progressão continuada, ciclos de formação e ciclos de aprendizagem. Essas denominações não podem ser tomadas como sinônimas.

De acordo com Mainardes (2001), a promoção automática centra sua preocupação no acesso e permanência escolar independente dos progressos terem sido alcançados sob a justificativa de reduzir as altas taxas de reprovação e desperdício de recursos financeiros. Vale salientar que ela não garante por si só a melhoria da qualidade de ensino, sua única intenção era descongestionar o sistema de ensino. 
A progressão continuada é mais uma forma de organização escolar assegurada pela LDB (BRASIL, 1996), no parágrafo $1^{\circ}$ do inciso IV do art. 32. Consiste numa tentativa de racionalização do currículo escolar para diminuir a reprovação e a aceleração dos alunos. Constitui-se como estratégia para viabilizar a universalização do ensino garantindo acesso e permanência na escola. Não necessariamente rompe com o sistema seriado, mas procura favorecer uma avaliação contínua do processo, promovendo diferentes formas de recuperação para garantir o êxito dos estudantes.

Os ciclos de formação, conforme Mainardes (2007) estão concatenados às fases do desenvolvimento humano e sugerem mudanças radicais tanto no currículo quanto na organização escolar, impossibilitando a reprovação ao longo do ensino fundamental.

Já os ciclos de aprendizagem constituem uma forma de organização escolar através de grupos, promovendo os alunos tomando como base a idade cronológica. Para Mainardes (2007) esses ciclos propõem rupturas menos radicais no currículo escolar, metodologia, avaliação, sendo a retenção permitida ao final de cada ciclo.

No âmbito do município do Recife, a modalidade ciclos de aprendizagem está em vigor desde 2001 e vêm interferindo na estrutura e funcionamento das unidades escolares. Eles constituem uma forma de organização escolar através de grupos, organizando os alunos tomando como base suas competências e procurando reduzir as distorções idade série muito comuns nesse sistema até 2001. Eles propõem rupturas no currículo escolar, metodologia, avaliação, sendo a retenção permitida ao final de cada ciclo.

Conforme a proposta (RECIFE, 2002), utilizando essa nova organização a escola passa a assegurar a construção da identidade cidadã. De modo que o sujeito aprende a valorizar sua cultura enfrentando os desafios, construindo seu caminho na relação com os outros, a cidadania deixa de ser algo apenas proclamado e passa a integrar os direitos sociais básicos. Nesse contexto a escola deve relacionar as aprendizagens às práticas sociais e todos os educadores devem estar comprometidos com a transformação social, repensar sua visão de mundo, planejar, agir e contribuir para a integração coletiva da escola nesses novos tempos.

Os ciclos de aprendizagem no Recife (2002), como prevê a proposta, têm como base a reorganização do espaço, tempo escolar e da prática pedagógica, num processo contínuo respeitando a diversidade e os diferentes tempos dos alunos para aprender. Considera o ritmo de aprendizagem de cada um e advoga que a avaliação deve ser realizada de forma dinâmica, contínua e processual 


\section{Os ciclos na história da educação brasileira}

A década de 50 registra várias discussões sobre como garantir o sucesso escolar, entre elas o fenômeno da promoção automática. Barreto e Mitrulis (2001) observam que a retenção já era vista como um obstáculo tanto para os órgãos financiadores, quanto para o processo de aprendizagem dos alunos. A contradição entre 0 aumento de vagas versus a qualidade do ensino também era muito forte. Almeida Júnior (1957) foi enfático ao recomendar o fim da repetência escolar. Para ele pouco importava o tipo de política que iria ser implantada, pois antes de qualquer coisa dever-se-ia preparar os professores para trabalharem com uma concepção de ensino menos seletiva, que não priorizasse apenas os conteúdos, mas buscasse compreender o aluno em seus problemas sociais, buscando medidas para saná-los.

Nas décadas de 60 e 70, a educação ainda permanecia com altos índices de reprovação e evasão. Alguns estados, mesmo que de maneira pontual, decidiram flexibilizar a organização do currículo escolar implantando alternativas ao fracasso escolar, como foi o caso de Santa Catarina.

A década de 80 é marcada pela adoção de ciclos de alfabetização por vários governos estaduais. Durante o processo de redemocratização do pais, os governos do Sul e Sudeste liderados pelo PMDB e PDT, adotaram medidas de reestruturação do currículo escolar. Este movimento fez com que três estados adotassem o chamado ciclo básico: São Paulo, Minas Gerais e Paraná.

0 ciclo básico reestruturava as antigas $1^{\text {a }}$ e $2^{\text {a }}$ séries do $1^{\circ} \mathrm{grau}{ }^{1}$, eliminando a reprovação no final da $1^{\text {a }}$ série, garantindo a continuidade dos estudos. Essa mudança proporcionava maiores possibilidades de sucesso para os alunos com dificuldades. Mesmo com os percalços de sua implementação, o ciclo básico constituiu-se como modelo de referência para outros estados a exemplo do Rio de Janeiro com a criação das escolas integrais (bloco único) implantadas em 1994.

Freitas (2003) afirma que os ciclos de aprendizagem procuram romper com o regime seriado que tem em sua origem uma lógica de dominação e exclusão. Essa lógica é uma construção histórica e produz enormes taxas de reprovação, sem viabilizar o desempenho acadêmico dos alunos. Esse fracasso se revela, dentre outras coisas, através do modo como o professor avalia os seus alunos, privilegiando a forma classificatória, verificando se eles dominam habilidades e conteúdos através de provas, testes, trabalhos. Essa forma de avaliar tem sido contestada, pois focaliza apenas o produto, como se o que antecedesse a ele, 0 processo, não fosse relevante.

\footnotetext{
${ }^{1}$ As diretrizes e bases para o ensino de $1^{\circ}$ e $2^{\circ}$ graus até 1996 foram fixadas pela Lei 5.692 (BRASIL, 1971), que conforme preconiza o seu art. $8^{\circ}$, o currículo escolar deveria ser organizado por séries anuais de disciplinas ou áreas de estudo.
} 


\section{Ciclos de aprendizagem: breve estado da pesquisa}

A discussão sobre ciclos de aprendizagem tem sido alvo de muitos debates e pesquisas sob diferentes enfoques nas últimas décadas. Os estudos de Arroyo (1999), Garcia (2001), Palma Filho, Alves e Duran (2003), Jacomini (2004, 2007), Glória (2002), Glória e Mafra (2004), e Gomes (2004), focalizam essa forma de organização escolar sob diferentes aspectos.

Arroyo (1999) questiona os tipos de profissionais formados para atuar na proposta do regime de ciclos com suas exigências e fundamentos. Argumenta que, desde que foram incorporados à LDB (BRASIL, 1996), os ciclos não são apenas mais uma proposta inovadora, pois muitas são as escolas que adotaram essa forma de organização de ensino.

Garcia (2001) analisou a validade da política de ciclos na rede estadual de São Paulo. Segundo a autora, os professores consideram que no sistema seriado era possivel obter resultados mais eficazes do que com o sistema de ciclos. Essa insatisfação por parte dos professores impulsionou a autora a investigar a aceitação das mudanças na educação pelos docentes e sua relação com a qualidade do ensino. Constatou que os professores não podem ser culpados pelo insucesso dos ciclos, visto que eles são vítimas dessa política e as condições que determinam os caminhos da educação não são conjunturais, são estruturais.

Em artigo, intitulado "A escola dos que passam sem saber: a prática da não retenção escolar na narrativa de alunos e familiares", Glória (2002) estudou como os pais e alunos entendem a proposta da não retenção, escola plural e implicações desse princípio na continuidade dos estudos dos alunos. Os resultados apontaram que, para os atores entrevistados, a escola não tem cumprido o papel, que para eles é fundamental: a preparação para o mercado de trabalho. Essa consequência é atribuída à proposta de não retenção escolar, que tem aprovado os seus filhos sem que eles dominem o mínimo exigido por esse mercado.

Na coletânea "Ciclo básico em São Paulo: memórias da educação nos anos de 1980", Palma Filho, Alves e Duran (2003) reúnem uma série de artigos que analisam o ciclo básico, em São Paulo. Na obra discutem: ações efetivadas pela Secretaria da Educação de Estado de São Paulo (1983-1986) focalizando a adoção do ciclo básico; o significado dessa política; questões emergentes durante sua implementação e a formação continuada dos agentes educacionais para atuar no ciclo básico.

Jacomini (2004) discute a atuação dos educadores no processo de implantação dos ciclos e progressão continuada em quatro momentos distintos no estado de São Paulo. Faz uma análise documental da reforma de 1967-1968, implantação do Ciclo Básico no estado (1983-1984), adoção das propostas ciclo básico e progres- 
são continuada na rede estadual de São Paulo no ano de 1998. Jacomini percebe uma constância das dificuldades manifestadas pelos professores nos diferentes momentos analisados. Conclui enfatizando a necessidade de mudança de postura frente aos condicionantes, porém admite que esta exige tempo e reflexão por parte dos envolvidos no sistema escolar.

Em investigação sobre políticas de implementação e prática docente na rede municipal de São Paulo (1992- 2001), Jacomini (2007), analisa a dinâmica entre os diferentes segmentos do estado, trabalhadores e usuários da escola na nova proposta. Conclui afirmando que à medida que os educadores não se apropriaram da lógica dos ciclos, eles continuarão a vê-los como algo exterior, desligada da prática docente.

Em pesquisa sobre as percepções dos professores concernentes à proposta da não retenção escolar na rede municipal de Belo Horizonte, Glória e Mafra (2004) revelam a resistência por parte de alguns professores na aceitação e incorporação da proposta de ciclos. As autoras acrescentam que essa resistência à proposta ainda é muito forte e, para os professores, a exclusão permanece mesmo com o princípio da não retenção escolar.

Gomes (2004) faz uma retrospectiva de cerca de quinze anos de pesquisas publicadas sobre ciclos indagando sobre os aspectos favoráveis e desfavoráveis, acertos e enganos cometidos com a implantação dessa politica. Apresenta resultados mistos revelando menores índices de retenção e evasão depois dos ciclos. Contudo, o dado mais forte revelado pelo autor é que a sombra da seriação mantida pelos docentes ainda perdura por trás dos ciclos.

Com esse breve recorte da literatura sobre o tema, podemos admitir que têm sido escassas as produções sobre ciclos de aprendizagem que tomam a Teoria das Representações Sociais como referencial. E, apoiando-se nesta teoria este artigo procura responder às seguintes questões: Quais os sentidos e os significados atribuídos pelos professores da rede municipal de ensino do Recife aos ciclos de aprendizagem? De que maneira vêm reagindo a essa proposta?

Nesse quadro de preocupações, buscamos identificar o núcleo central e sistema periférico das representações sociais de ciclos de aprendizagem entre esses profissionais. Desta forma, procuramos valorizar o campo das produções simbólicas onde se expressam os saberes e práticas dos sujeitos sociais. Admitimos que estudar os ciclos de aprendizagem a partir da Teoria das Representações Sociais constitui-se de grande relevância, visto que as representações que os sujeitos possuem revelam os significados atribuídos ao fenômeno. Ao adotarmos essa teoria, procuramos compreender não somente o quê e como as pessoas representam um objeto, mas, também, como e porque fazem daquela forma. Estamos interessados em investigar como professo- 
res, principais atores do processo de organização curricular, compreendem os ciclos de aprendizagem e suas implicações, a partir de uma perspectiva psicossocial, uma vez que as representações sociais têm ocupado um espaço importante e têm sido uma ferramenta para a compreensão da complexidade, das aparentes discrepâncias e dicotomias que surgem no processo de conhecimento de um dado fenômeno social, tendo como pressuposto o efeito do cotidiano e das práticas em sua construção.

\section{Sobre a Teoria das Representações Sociais}

0 termo representações sociais surgiu em 1961 com o trabalho de Serge Moscovici (1978), "A representação social da Psicanálise". Nesse estudo o autor mostra o que sabe a população parisiense sobre o fenômeno da psicanálise, bem como o impacto deste saber na vida daquelas pessoas. Com essa obra nascia uma nova teoria, uma "psicossociologia do conhecimento" (SÁ, 1995).

Moscovici queria ainda saber como são partilhados os conhecimentos e de que modo um conhecimento cientifico se transforma em um saber prático, numa teoria do senso comum. Sua tese é a de que as tentativas de explicação do mundo e dos objetos sociais constituem-se como representações sociais. Essas se revelam nas falas e ações dos indivíduos. Na visão do autor, representar não significa reproduzir ou duplicar, significa muito mais que isso, quer dizer reconstruir. Representar é participar ativamente da construção da sociedade e de si. No dizer de Jodelet (2001, p. 22) a representação social é: "uma forma de conhecimento, socialmente elaborada e partilhada, com um objetivo prático".

A Teoria das Representações Sociais já está de certa maneira consolidada no meio acadêmico e conforme Sá (1998) desdobra-se em pelo menos três abordagens: a primeira é uma continuidade da obra original, tem um viés antropológico e tem sido mais difundida por Denise Jodelet (2001); a segunda, através de Willem Doise (1990), centrase nas condições de produção e circulação das representações sociais e a terceira surge em Aix-en-Provence, sendo representada por Jean Claude Abric (1998), que dá ênfase a dimensão cognitivo-estrutural conhecida como Teoria do Núcleo Central.

A Teoria do Núcleo Central (TNC) foi proposta por Jean Claude Abric (1998) no ano de 1976. 0 autor sustenta a hipótese de que toda representação social está organizada em torno de um núcleo central e um sistema periférico. 0 núcleo central está relacionado à memória coletiva dando significação, consistência e permanência à representação sendo, portanto, estável e resistente a mudanças.

Esse núcleo é composto pelos elementos estáveis ou mais permanentes da representação social, sendo estes de natureza normativa e funcional. Os aspectos funcionais estão ligados à natureza do objeto representado e os normativos dizem respeito aos valores e normas sociais pertencentes ao meio social do grupo. 
O sistema periférico é responsável pela atualização e contextualização da representação. Para Flament (2001) a periferia de uma representação social é considerada um "para-choque" entre a realidade e um núcleo central que não muda facilmente.

Conforme a Teoria do Núcleo Central (ABRIC, 1998), uma representação social constitui-se como um conjunto organizado e estruturado de informações, crenças, opiniões e atitudes, composta de dois subsistemas - o central e o periférico -, que funcionam exatamente como uma entidade, onde cada parte tem um papel especifico e complementar.

\section{Metodologia}

0 estudo é de natureza qualitativa e procura delinear o núcleo central e o sistema periférico das representações sociais de ciclos de aprendizagem entre professores através da Associação Livre de Palavras. A técnica de associação livre de palavras é um tipo de investigação aberta que se estrutura a partir da evocação de respostas dadas com base em um estímulo indutor, o que permite colocar, em evidência, universos semânticos relacionados a determinado objeto. No nosso caso, a técnica consistiu em pedir ao professor(a) que escrevesse quatro palavras que lhe viessem imediatamente à lembrança ao ouvir a expressão "ciclos de aprendizagem é...". Em seguida, solicitamos que o mesmo elegesse dentre as palavras evocadas a que julgasse ser a mais importante e justificasse a importância dada à palavra.

0 cenário da pesquisa é a rede municipal Recife- $\mathrm{PE}$, escolas de diferentes Regiões Político Administrativas (RPAs). A escolha se deve à implantação em 2001 dos ciclos de aprendizagem nesse sistema municipal. Aplicamos a técnica de associação a professores de 37 escolas, localizadas em bairros diversos que apresentavam uma característica comum: todas atendem a uma população de baixa renda.

Participaram da pesquisa são 103 professores dos quatro ciclos do Ensino Fundamental sendo a sua grande maioria, ou seja, noventa e três deles do sexo feminino. A faixa etária predominante dos participantes é de 30 a 35 anos. Quanto à formação acadêmica destacamos que $64 \%$ dos participantes concluíram pós-graduação (lato sensu).

Os dados foram organizados e processados através do software EVOC, elaborado por Pierre Vergès (2002), e com base nesse processamento chegamos ao provável núcleo central e sistema periférico da representação social de ciclos de aprendizagem entre professores. 0 software EVOC permite a realização de cálculos estatísticos, construindo matrizes de co-ocorrências, os quais servem de base para a construção do quadro de quatro casas.

O EVOC é composto por dezesseis programas, os quais executam funções diferenciadas. Para o nosso estudo utilizamos cinco dos programas que com- 
põem o software. 0 primeiro é o Lexique, cuja função é isolar as unidades lexicais do arquivo utilizado. 0 segundo, Trievoc, realiza uma triagem das evocações, organizando-as por ordem alfabética. 0 Nettoie realiza uma limpeza do arquivo, eliminando possiveis erros de digitação, unidades lexicais e ortografia. Em seguida o Rangmot disponibiliza uma lista de todas as palavras evocadas em ordem alfabética, indicando quantas vezes elas foram evocada e a ordem de sua evocação. Ainda, o Rangmot fornece: a frequência total de cada palavra; a média ponderada da ordem de evocação de cada palavra; frequência total e média geral das ordens de evocação. 0 último procedimento do EVOC foi o uso do programa Rangfrq, também chamado de Tabrgfrq, que organiza num quadro de quatro casas os elementos que compõem o núcleo central e a periferia de uma representação.

Conforme Vergés (2002), os quatro quadrantes podem ser assim interpretados: no primeiro situam-se os elementos mais relevantes e, por isso, possiveis de constituírem o núcleo central de uma representação. Estes elementos são os mais prontamente evocados e citados com frequência elevada pelos sujeitos. 0 segundo e o terceiro quadrantes correspondem aos elementos menos salientes na estrutura da representação, contudo eles são significativos em sua organização. No segundo quadrante estão os elementos que obtiveram uma frequência alta, mas que foram citados em últimas posições; no terceiro quadrante encontram-se os elementos que foram citados numa frequência baixa, porém foram evocados primeiramente. No quarto quadrante estão os elementos que correspondem à periferia distante ou segunda periferia. Nele estão os elementos menos citados e menos evocados em primeira mão pelos sujeitos.

\section{Resultados e discussão}

0 resultado da associação livre foi uma lista com 412 palavras, sendo que destas $205(49,75 \%)$ eram diferentes. Observamos que a palavra "aprendizagem" apareceu com o maior número de evocações (18), enquanto 145 palavras foram evocadas apenas uma só vez.

No Quadro 1, oferecido pelo EVOC, ficam distribuídos os dados das ocorrências em quatro quadrantes, que nos permitem visualizar o núcleo central, os elementos intermediários, de contraste e periféricos de uma representação. Assim, para interpretar o quadro, conforme Oliveira, Marques e Tosoli (2005), procedemos da seguinte forma: no quadrante superior esquerdo localizam-se as palavras que constituem, muito provavelmente, o núcleo central da representação, no quadrante superior direito a primeira periferia, no quadrante inferior esquerdo, os elementos de contraste e, por fim, no quadrante inferior direito, a segunda periferia da representação social. 


\begin{tabular}{|c|c|c|c|c|c|}
\hline$f>=10$ e $0 M E<2,5$ & & & $\mathrm{f}>=10$ e $0 \mathrm{ME}>=2,5$ & & \\
\hline & $f$ & OME & & $f$ & OME \\
\hline Avaliação & 13 & 2,38 & Aprendizagem & 18 & 3,00 \\
\hline Continuidade & 17 & 1,88 & & & \\
\hline Oportunidade & 12 & 2,00 & & & \\
\hline Processo & 12 & 2,16 & & & \\
\hline Respeito & 11 & 2,36 & & & \\
\hline Tempo & 11 & 2,27 & & & \\
\hline $\mathrm{f}<10$ e $0 \mathrm{ME}<2,5$ & & & $\mathrm{f}<10$ e $0 \mathrm{ME}>=2,5$ & & \\
\hline & $f$ & OME & & $f$ & OME \\
\hline Alfabetização & 5 & 2,00 & Competência & 6 & 3,16 \\
\hline Aprovação & 6 & 2,00 & Compromisso & 7 & 3,00 \\
\hline Avanço & 6 & 2,00 & Conhecimento & 7 & 2,85 \\
\hline Construção & 9 & 2,11 & Desenvolvimento & 7 & 3,00 \\
\hline Promoção & 7 & 1,28 & Dificuldades & 5 & 2,80 \\
\hline
\end{tabular}

Quadro 1 - Possíveis elementos centrais e periféricos da representação social de ciclos de aprendizagem.

No primeiro quadrante estão situados os prováveis elementos centrais: avaliação, continuidade, oportunidade, processo, respeito e tempo. Já os elementos periféricos da representação social de ciclos de aprendizagem encontram-se distribuidos nos três demais quadrantes: no superior direito, a palavra "aprendizagem" é o único elemento pertencente à primeira periferia; no quadrante inferior esquerdo estão, as palavras alfabetização, aprovação, avanço, construção, promoção e constituem a zona de contraste, e, no quadrante inferior direito, segunda periferia, estão localizadas as palavras: competência, compromisso, conhecimento, desenvolvimento e dificuldades. Podemos dizer que esses elementos indicam a gama de sentidos atribuídos pelos professores a essa forma de organização curricular.

No possível núcleo central a palavra "avaliação" ocupa este quadrante certamente devido à sua ênfase na proposta dos ciclos de aprendizagem (RECIFE, 2002), ao preconizar a ruptura com o sistema de avaliação classificatória, baseado em notas e provas. Como salienta Souza (2007), a avaliação, antes era tomada como instrumento de controle e medição, voltada para a classificação dos alunos. Em contraposição, a avaliação nos ciclos assume uma natureza processual, formativa, que visa a acompanhar o aluno durante todo o seu percurso de aprendizagem.

Nas justificativas dos professores para a evocação e escolha das palavras mais importantes, vários aspectos da avaliação formativa foram destacados, como: a oportunidade que o professor tem de se autoavaliar à medida que avalia seus alu- 
nos. Essas justificativas mostram que os docentes estão-se apropriando do novo discurso sobre a avaliação, pois se remetem a esta prática como processual, formativa, diagnóstica e contínua. Como afirma um dos participantes²:

[...] destaco a avaliação, já que é algo contínuo no processo de ensino/aprendizagem aquilo que foi eficaz. Ao mesmo tempo o professor pode verificar a sua própria atuação. Em se retirar a prova formal escrita que não detectava conhecimento do educando, esse novo meio sistemático, tornou-se mais adequado (Prof. 59).

A palavra continuidade, segundo elemento do suposto núcleo central, pode ser interpretada como oportunidade de assegurar aos alunos a continuidade nos estudos, não interrompendo o processo de desenvolvimento e aprendizagem. Os ciclos permitem aos alunos cumprir as etapas obrigatórias do ensino em um maior tempo de permanência na escola, sem as interrupções ocasionadas pela reprovação, que dificultam a aquisição de aprendizagens significativas.

Na mesma linha de interpretação anterior, a palavra oportunidade aparece no sentido de se oferecer mais uma chance ao aluno que não conseguiu alcançar todas as competências previstas durante um ano. Os ciclos, diferentemente das pedagogias visíveis, não o exclui através de reprovações, mas permite a esse aluno prosseguir na sua formação básica. Bernstein (1990 apud MAINARDES, 2007) afirma que as pedagogias visíveis têm o ensino centrado no professor, dão muita ênfase ao desempenho e aos resultados demonstrados pela criança em relação a um padrão externo. Já as pedagogias invisíveis estão mais voltadas para o processo de aprendizagem, sendo seus critérios mais implícitos e difusos. (MAINARDES, 2007)

A palavra processo indica a ênfase dada nos ciclos ao caráter processual de ensino e aprendizagem de modo a valorizar o percurso feito pelo aluno na construção do conhecimento. A justificativa apresentada para a palavra processo sinaliza nessa direção:

a organização do ensino em ciclos contribui bastante no processo educativo permitindo tomada de decisões no percurso da aprendizagem do aluno buscando novas ações educativas trabalhando conceitos e construindo as competências de cada área observando as possibilidades de cada um numa ação coletiva tornando a aprendizagem mais significativa. (Prof. 56).

\footnotetext{
2 Os participantes desta pesquisa foram codificados de acordo com a ordem de numeração do protocolo. Por exemplo, Prof. 59, são referências aos escritos do qüinquagésimo nono participante. Lembramos que as justificativas foram transcritas para este artigo do modo como os professores as escreveram.
} 
As palavras tempo e respeito, também integrantes do suposto núcleo central, estão intrinsecamente relacionadas entre si, por enfatizarem o respeito às fases de desenvolvimento da criança. Percebemos, nos seus depoimentos, certa sintonia com o que está descrito na proposta de reorganização dos tempos e espaços educativos. A proposta da Prefeitura do Recife (2002, p. 136) defende "uma política de inclusão que busca respeitar a diversidade e os diferentes tempos para aprender.

Os resultados aqui apresentados permitem indicar notável saliência dos elementos avaliação, continuidade, oportunidade, processo, tempo e respeito nas representações de ciclos de aprendizagem, os quais são correspondentes ao que é preconizado na proposta oficial.

Os elementos periféricos da representação social de ciclos de aprendizagem encontram-se distribuídos nos três demais quadrantes e os mesmos possibilitam perceber amplos sentidos atribuídos pelos professores a essa forma de organização curricular.

Sobre o sistema periférico cumpre pontuar que ele é complemento indispensável do central, uma vez que protege esse núcleo, atualiza e contextualiza constantemente suas determinações normativas, permitindo uma diferenciação em função das experiências cotidianas nas quais os indivíduos estão imersos. Em poucas palavras, os elementos do sistema periférico fazem a interface entre a realidade concreta e o sistema central. Com essa consideração queremos enfatizar seu valor na configuração das representações sociais de ciclos de aprendizagem.

No quadrante superior direito situa-se a palavra "aprendizagem" como único elemento pertencente à primeira periferia. Lembramos que a concepção de aprendizagem que fundamenta a proposta de ciclos de aprendizagem considera aluno e professor como sujeitos do processo de ensino e aprendizagem, sendo esse processo resultante da ação e reflexão do aluno frente aos novos conhecimentos que lhes são apresentados. 0 aluno, como corrobora Weisz (2000), é considerado alguém que já tem um conhecimento prévio e que, ao interagir com os novos conhecimentos, atribui-Ihes sentidos e significados internalizando-os.

As palavras alfabetização, aprovação, avanço, construção e promoção, posicionadas no quadrante inferior esquerdo, segundo Oliveira, Marques e Tosoli (2005, p. 4), constituem a zona de contraste, ela "comporta elementos que caracterizam variações da representação em função de subgrupos, sem, no entanto, modificar os elementos centrais e a própria representação, ou seja, denotam mudanças ou transição de uma representação social".

As palavras aprovação e promoção vão aparecer ora como sendo sinônimas, ora como opostas. Fernandes (2007) refere-se a esses termos como antagônicos. Para esta autora, quando pensamos no regime seriado, automaticamente, fazemos referência aos 
termos aprovação e reprovação. Já nos ciclos, nos referimos aos elementos promoção e retenção. Se formos por esse viés, o termo "aprovação" está associado à avaliação classificatória e meritocrática comum no regime seriado. A avaliação nessa ótica incidirá na verificação da aprendizagem, o aluno terá que dar um retorno de tudo o que o professor transmitiu para ser aprovado, já que essa estruturação curricular apóia-se nos conteúdos para organizar o tempo escolar. Se a recíproca não for verdadeira, o aluno será reprovado.

0 termo promoção evocado sete vezes, nos parece contraditório se também adotarmos a perspectiva de Fernandes (2007). Segundo ela, a lógica dos ciclos de aprendizagem não postula a mera promoção automática dos alunos. Mas, seu sentido nos ciclos reside na reorganização dos tempos e espaços escolares levando em consideração as fases do desenvolvimento humano, o ritmo de aprendizagem de cada aluno. Conforme proclama a Proposta Recife (2002), os ciclos compreendem o processo de aprendizagem e desenvolvimento da criança em situações e contextos complexos. A aprovação nos ciclos não deve ser sinônimo de promoção automática, ou seja, aquela em que os alunos são aprovados sem dominar o mínimo de habilidades e competências exigidas para um ano ou tempo de escolaridade. Ela está pautada num viés processual, dinâmico e reflexivo, como também é tomada como momento de acompanhamento didático-pedagógico.

Implícita e explicitamente os participantes desta pesquisa desabafam sobre o fato do professor não ter mais como reter o aluno, já que lhe foi retirado o poder da reprovação escolar, bem como reclamam que os ciclos provocaram o desinteresse geral desses alunos, tendo em vista que eles sabem que serão aprovados em qualquer circunstância. Assim, os docentes, ao justificarem a escolha da palavra promoção como mais relevante, expressam que com a promoção automática, os alunos não manifestarão mais interesse pelos estudos. Chegam a afirmar: "Promoção [...] uma vez que não existe meio de reter o aluno para que o mesmo tenha outra oportunidade de aprender mais, e isto está tirando o interesse do mesmo que já sabe que vai ser promovido para outra série" (Prof. 58).

Alfabetização é outra palavra que compõe o quadrante inferior esquerdo. A esse respeito lembramos que a proposta de ciclos colocou em cheque a necessidade de se repensar o conceito de alfabetização e sua importância na vida do aluno. Nessa perspectiva mais atualizada de alfabetização, o professor deverá propiciar momentos que favoreçam a vivência dos usos sociais da leitura e da escrita. Corroborando nossa posição, Weisz (2000, p. 60) entende que o educador deve atuar como um facilitador conduzindo crianças a "participarem de situações sociais nas quais os textos reais sejam utilizados para pensar sobre as características e o funcionamento da língua escrita". A noção defendida pela autora também confirma as proposições da Proposta Recife (2002, p. 165), uma vez que o documento estimula o uso de diferentes linguagens na introdução da leitura e da escrita, bem como a utilização de "materiais escritos diversos como músicas, poesias, contos, a narrativa diária de histórias". 
Na nossa interpretação a palavra avanço, também integrante da zona de contraste, assume pelo menos dois sentidos quando nos voltamos para a literatura a respeito dos ciclos de aprendizagem. 0 primeiro relaciona-se ao fim da repetência, autores como Gomes (2004) ilustram bem esse aspecto, afirmando que a implantação dos ciclos representa um avanço no combate à reprovação e consequentemente ao fracasso escolar. 0 segundo refere-se à possibilidade de 0 aluno avançar no processo de escolarização, evitando a repetência e a evasão.

0 último elemento do terceiro quadrante inferior esquerdo é a palavra construção, tal termo está relacionado às abordagens construtivistas que consideram o aluno como sujeito importante no seu processo de aprendizagem. A proposta de ciclos de aprendizagem condena a idéia de que o aluno deve absorver os conteúdos, "usando como recurso o condicionamento estático estímuloresposta" (WEISZ, 2000, p. 60).

No quadrante inferior direito, segunda periferia da representação social de ciclos de aprendizagem, estão localizadas as palavras: competência, compromisso, conhecimento, desenvolvimento e dificuldades.

Para análise agrupamos as palavras conhecimento e desenvolvimento por estarmos diante de um grupo, cuja proposta curricular aproxima os dois elementos. Não obstante, com as contribuições da psicologia social, as noções de conhecimento sofreram diversos avanços, tendo em vista o esforço em compreender como o sujeito se desenvolve e aprende. Autores como Piaget e Vygotsky rompem com a perspectiva empirista que enfatiza a memorização e internalização dos conteúdos como essenciais à aprendizagem do aluno. A lógica interacionista de Piaget e a sociointeracionista de Vygotsky incorporam os fatores biológico e social ao fenômeno da aprendizagem, defendendo que o processo de desenvolvimento do individuo está intrinsecamente concatenado ao contexto social em que ele está inserido.

0 termo conhecimento também se reveste de significado para os ciclos de aprendizagem, pois remete a uma ação pedagógica do educador nas bases construtivistas, voltada não apenas para o conhecimento que o aluno já possui (o produto), mas para as suas potencialidades (o processo), proporcionando atividades para que possibilitem o avanço na construção do conhecimento.

Os elementos compromisso e competência foram também analisados em conjunto, pois são imprescindiveis à proposta dos ciclos de aprendizagem. Empreender uma prática capaz de garantir o sucesso acadêmico, ou seja, garantir o acesso aos conhecimentos e desenvolver certas competências mínimas essenciais constitui-se como condição fundamental para que o educando consiga alcançar níveis de aprofundamento e complexidade mais elevados. 
0 elemento dificuldades, ressaltado pelos docentes várias vezes ao longo da pesquisa, reflete os mesmos aspectos enfatizados por eles na ocasião da implantação da proposta dos ciclos no ano de 2001. As inquietações e dificuldades envolvem bases conceituais do processo de ensino e aprendizagem, conteúdos curriculares, sistema de avaliação, formação continuada, falta de diálogo entre os campos oficial e pedagógico, como também entraves relacionados à falta de condicionantes estruturais e pedagógicos nas escolas do município. Alguns docentes no decorrer da aplicação da associação livre queixavam-se da forma como foi implantada, apenas para descongestionar o sistema em função do elevado índice de reprovações e não como forma de melhorar as condições de ensino e aprendizagem. Referiram-se ainda, a problemas relacionados à estrutura física e humana das instituições escolares, falta de espaços de aprendizagem para os alunos com dificuldades e desvantagens. Um outro problema ressaltado pelos professores foi a falta de orientação e capacitação para os profissionais da rede pública, além dos baixos salários e não valorização da educação no país.

\section{Considerações finais}

Os resultados obtidos permitem indicar notável saliência dos elementos centrais avaliação, continuidade, processo, tempo e respeito e periféricos aprendizagem, alfabetização, avanço, aprovação, promoção, construção, competência, desenvolvimento, dificuldades, compromisso e conhecimento assumem. Tais elementos podem ser tomados como os mais significativos para a proposta dos ciclos. Isto vem corroborar que os docentes não estão inocentes quanto aos princípios apregoados pela proposta dos ciclos de aprendizagem.

A partir dos resultados obtidos podemos afirmar que os docentes apresentam um discurso racionalizado, ou seja, embora na prática critiquem e rechacem os ciclos de aprendizagem, evocam palavras que estão em pleno acordo com a nova organização curricular vigente na rede municipal. Sugerimos, portanto, a partir dos desses resultados, o desenvolvimento de pesquisas de natureza etnográfica que focalizem a prática pedagógica do professor nessa nova forma de organização curricular, pois como orienta Moscovici (1978, p. 290) "uma teoria jamais recobre todos os dados empíricos coletados. É ultrapassada por ele e os ultrapassa".

Por fim, convém destacar que este estudo sinaliza outras direções e aprofundamentos para o estudo das representações sociais de ciclos de aprendizagem, pois como afirma Sá (1998), sendo elas difusas, fugidias, multifacetadas, dificultariam sua captura. Nossa pesquisa indica, portanto, a necessidade de estudos mais densos das práticas cotidianas dos docentes, para depreender aspectos das representações sociais que nos pareceram pouco revelados. 


\section{Referências}

ABRIC, J. C. A abordagem estrutural das representações sociais. In: MOREIRA, A. S. P; OLIVEIRA, D. C. de. Estudos interdisciplinares de representação social. Goiânia: Ed. AB, 1998.

ALMEIDA JÚNIOR, A. F. Repetência ou promoção automática?. Revista Brasileira de Estudos Pedagógicos, Brasília, DF, v. 27, n. 65, p. 3-15, jan./mar. 1957.

ARROYO. M. Ciclos de desenvolvimento humano e formação de educadores. Educação e Sociedade, Campinas, SP, n. 68, dez. 1999.

BARRETO, E. S. S; MITRULIS, E. Os ciclos escolares: elementos de uma trajetória. Cadernos de Pesquisa, São Paulo, n. 108, p. 27-48, nov. 1999.

BRASIL. Lei $n^{\circ}$. 5.692, de 11 de agosto de 1971. Fixa Diretrizes e Bases para 0 ensino de $1^{\circ}$ e $2^{\circ}$ graus, e dá outras providências. Diário Oficial da União, Brasília, DF, 12 ago. 1971. Disponivel em: < http://www.planalto.gov.br/ccivil_03/Leis/ L5692.htm>. Acesso em: 12 jul. 2010.

BRASIL. Lei n 9.394, de 20 de dezembro de 1996. Institui as Diretrizes e Bases da Educação Nacional. Diário [da] República Federativa do Brasil, Brasilia, DF, 23 dez. 1996.

DOISE, W. Les représentations sociales. In: GHIGLIONE, R.; BONNET, C.; RICHARD, J. F. Traité de psychologie cognitive. Paris: Dunod, 1990. v. 3.

FLAMENT, C. Estrutura e dinâmica das representações sociais. In: JODELET. D. (Org.). Representações sociais. Rio de Janeiro: EdUERJ, 2001.

FERNANDES, C. O. A organização da escolaridade em ciclos: impactos na escola. In: REUNIÃO ANUAL DA ANPED, 30., 2007, Caxambu. Anais... Caxambu: ANPED, 2007. Disponível em: <www.anped.org.br>. Acesso em: 12 jul. 2010.

FREITAS, L.C. Ciclos, seriação e avaliação: confronto de lógicas. São Paulo: Moderna, 2003. (Coleção Cotidiano Escolar).

GARCIA, C. A. A. Ciclos e qualidade de ensino: uma relação complexa. In: REUNIÃO ANUAL DA ANPED, 24. 2001, Caxambu. Anais... Caxambu, MG: ANPED, 2001. Disponível em: <www.anped.org.br >. Acesso em: 12 jul. 2010.

GLÓRIA. D. M. A.; MAFRA, L. D. A. A prática da não retenção na narrativa de professores do ensino fundamental: dificuldades e avanços na busca do sucesso escolar. Educação e Pesquisa, São Paulo, v. 30, n. 2, p. 231-250, maio/ago. 2004. 
GLÓRIA, D. M. A. A escola dos que passam sem saber: a prática da não retenção na narrativa de alunos e familiares. In: REUNIÃO ANUAL DA ANPED, 25., 2002, Caxambu. Trabalhos apresentados... Caxambu, MG: ANPED, 2002. Disponível em: <www.anped.org.br>. Acesso em: 12 jul. 2010.

GOMES, C. A. Quinze anos de ciclos no ensino fundamental: um balanço das pesquisas sobre a sua implantação. Revista Brasileira de Educação. Rio de Janeiro, n. 25, p. 39-52, jan./abr. 2004.

INEP. Sincronismo idade/série: um indicador de produtividade do sistema educacional brasileiro. Brasília, DF, 2003. (Série documental; 11).

JACOMINI, M. A. A escola e os educadores em tempos de ciclos e progressão continuada: uma análise das experiências no estado de São Paulo. Educação e Pesquisa. São Paulo, v.30, n³, p. 401-418, set/dez. 2004.

- Os educadores e a organização do ensino em ciclos na rede municipal de São Paulo (1992-2001). Revista Factus, São Paulo, p. 95-112. p.65, abril. 2007.

JODELET, D. Representação social: um domínio em expansão. In: (Org.). Representações sociais. Rio de Janeiro: EdUERJ, 2001.

MAINARDES, J. A organização da escolaridade em ciclos: ainda um desafio. In: FRANCO, C. (Org.) Avaliação, ciclos e promoção na educação. Porto Alegre: Artmed. 2001.

MAINARDES, J. Reinterpretando os ciclos de aprendizagem. São Paulo. Cortez. 2007.

MOSCOVICl, S. A representação social da psicanálise. Tradução de Álvaro Cabral. Rio de Janeiro: Zahar, 1978.

OLIVEIRA, C. D.; MARQUES S. C.; TOSOLI, A. M. Analise das evocações livres: uma técnica de análise estrutural das representações sociais. In: MOREIRA, A. P. et al. (Org.). Perspectivas teórico-metodológicas em representações sociais. João Pessoa: Ed. da UFPB, 2005.

PALMA FILHO, J. C.; ALVES, M. L.; DURAN, M. C. G. Ciclo básico em São Paulo: memórias da educação nos anos 1980. São Paulo, Xamã, 2003.

RECIFE (PE). Prefeitura Municipal. Secretaria de Educação. Proposta pedagógica da rede municipal de ensino do Recife: construindo competências. Recife, 2002. 
SÁ, C. P. Representações sociais: o conceito e o estado atual da teoria. In: SPINK, M. J. P. (Org.). O conhecimento no cotidiano. São Paulo: Brasiliense, 1995.

SÁ, C. P. A construção do objeto de pesquisa em representações sociais. Rio de Janeiro. EDUERJ, 1998.

SETUBAL, M. A. Os programas de correção de fluxo no contexto das políticas educacionais contemporâneas. Em Aberto. Brasília, DF, v. 17, n 71, p. 9-19, 2000.

SOUSA, S. Z. Avaliação, ciclos e qualidade do Ensino Fundamental: uma relação a ser construída. Estudos Avançados, v. 21, p. 27-44, 2007.

VĖRGES, P. Conjunto de programas que permitem a análise de evocações:

EVOC: manual. Versão 5. Aix en Provence: [S. n.\} 2002

WEISZ, T. 0 diálogo entre o ensino e a aprendizagem. 2. ed. São Paulo: Ática, 2000.

Recebido em: 17/06/2009

Aceito para publicação em: 19/10/2009 